\title{
Renal Primitive Malignant Tumor with Endocrine Activity
}

\author{
Ning Xu ${ }^{a}$ Mei-Shan Jin ${ }^{b}$ Liang Chen ${ }^{c}$ Chun-Xi Wang ${ }^{a}$ Shou-Tian Sun ${ }^{a}$ \\ Ai-Ping Shid

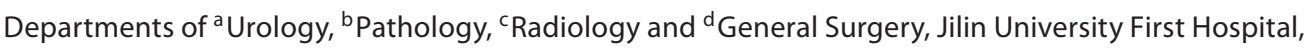 \\ Changchun, China
}

\section{Key Words}

Renal neoplasm • Primitive neuroectodermal tumor •

EWS/FLI1 fusion gene

\begin{abstract}
Objective: To report a hypertensive and systematically pigmented female with primitive neuroectodermal tumors. Clinical Presentation and Intervention: A female patient presented with a complaint of right flank pain. She had a right renal space-occupying lesion, underwent right radical nephrectomy, and returned to normotensive postoperatively. The pathological examination identified typical primitive neuroectodermal tumor histology. During a 60-month follow-up period, she remained normotensive and demonstrated normal renal and adrenal functions. Conclusion: Early diagnosis and definitive surgery led to the patient's longterm survival.

Copyright $\odot 2012$ S. Karger AG, Basel
\end{abstract}

\section{Introduction}

Primitive neuroectodermal tumor (PNET), a rare neural crest tumor occurring usually in childhood, derives from neuroendocrine cells and is characterized by

\section{KARGER}

E-Mail karger@karger.ch www.karger.com/mpp

\section{(c) 2012 S. Karger AG, Basel} 1011-7571/13/0222-0200\$38.00/0

Karger

0 pen access

This is an Open Access article licensed under the terms of the Creative Commons Attribution- NonCommercial-NoDerivs 3.0 License (www.karger.com/OA-license), applicable to the online version of the article only. Distribution for non-commercial purposes only. the small round cells on its histological appearance [1]. As a highly aggressive sarcoma due to its poor differentiation, PNET is usually observed either within the central nervous system or peripheral soft tissues, but rarely involves kidneys. PNET needs to be differentiated from renal cell carcinoma and Wilm's tumor in case of renal involvement [2]. In the present report, we used immunohistochemistry and molecular cytogenetics to differentially diagnose PNET in an adult with endocrine symptoms mimicking Cushing's syndrome.

\section{Case Report}

A 33-year-old female complained of right flank pain for 6 months. She exhibited a right renal mass on ultrasonography and was subsequently referred to our urological unit for further treatment. On admission, she was hypertensive $(220 / 110 \mathrm{~mm} \mathrm{Hg})$ and systematically pigmented. A non-tender solid mass was palpable below the right costal margin. A repeated renal Doppler ultrasonography confirmed a well-vascularized intense solid mass that occupied the right renal lower polar. A contrast-enhanced CT scan showed a well-marginated heterogeneous tumor localized at the lower polar of the right kidney. The right renal upper polar was compressed with concurrent cortical atrophy and hydronephrosis, the right renal vein was compressed and displaced, and the adrenal glands exhibited a normal size and shape (fig. 1). Her renal function test was normal. Serum and urine cor- 


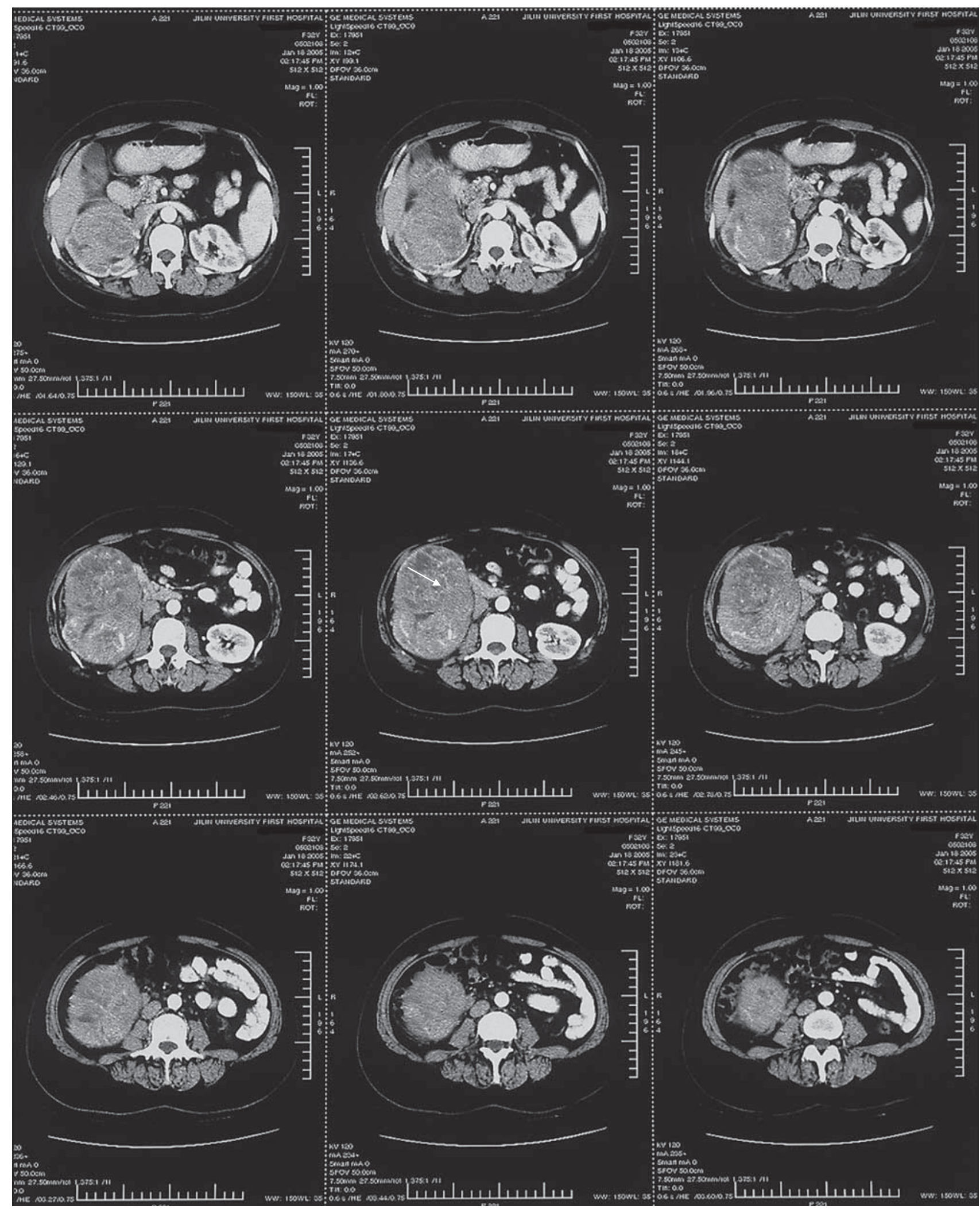

Fig. 1. Abdominal CT scan identified a $9.0 \times 12.0 \mathrm{~cm}$ clear-margined and internally heterogeneous solid tumor (arrow) located at the right renal lower polar. 
Fig. 2. Histology (a) and CD99 (MIC) immunohistochemistry (b) of the renal PNET $(400 \times)$.

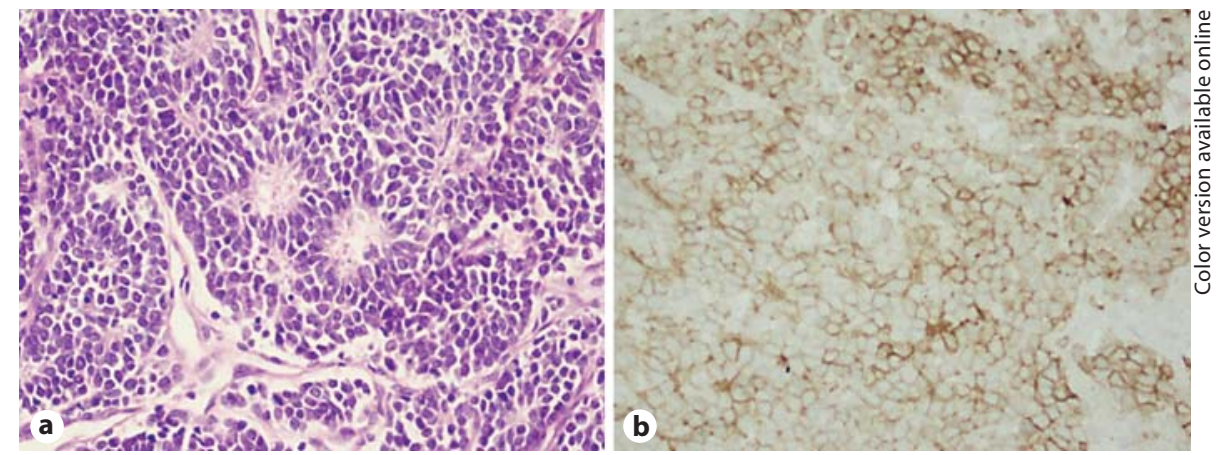

tisol levels were $409.613 \mathrm{ng} / \mathrm{ml}$ (35-200) and $9.3 \mathrm{ug} / 24 \mathrm{~h} \mathrm{(20-70),}$ respectively, at a 24 -hour urine output of $1,870 \mathrm{ml}$.

The patient received nifedipine controlled-release tablets $(30 \mathrm{mg}$ ) for 8 consecutive days, maintaining her blood pressure at 140/80 mm Hg preoperatively. She subsequently underwent right radical nephrectomy under general anesthesia. At surgery, a solid tumor of $13.0 \times 9.0 \times 7.0 \mathrm{~cm}$ was identified in the lower polar of right kidney. An en-bloc resection of the right kidney and tumor was performed, including the dissection of renal fascia, adipose capsule, and pedicle lympho-adipose tissues. Tumor thrombus was not palpated in the right renal vein, and lymphadenopathy was not detected in the renal area. The resected specimen weighed approximately $750 \mathrm{~g}$ and the transverse section was grey-whitish without any visible hemorrhagic lesions.

Pathological examination revealed that the tumor cells were small, round, in the uniformed size, and separated by fibers and vessels. The tumor cell nuclei were round or oval and heavily stained, the cytoplasm was lightly stained, and the pathological karyokinesis was frequently visible. Tumor cells were clustered into the loose rose-ring-like architecture (fig. 2a). There was no ectopic adrenal gland tissue detected in the resection specimen. Immunohistochemistry of paraffin sections revealed CD99 (+) (fig. 2b), vimentin (+), CgA (-), Sy (+), and EMA (-), confirming the diagnosis of renal PNET. RT-PCR with the forward primer of EWS exon 7 (TCC TAC AGC CAA GCT CCA AGT C) and the reverse primer of exon 6 (GTT GAG GCC AGA ATT CAT GTT A) identified the fusion gene EWS/FLI1 (261bp) in tumor tissues as compared to peritumor tissues [3].

Postoperatively, the patient was normotensive $(140 / 90 \mathrm{~mm}$ $\mathrm{Hg}$ ) and her systematic pigmentation resolved significantly. Radiotherapy or chemotherapy was not scheduled due to the patient's refusal. During follow-up, a routine CT scan at postoperative 20 months identified a single outward-growing tumor from the hepatic visceral side between S5 and S6, at a size of approximately $3 \times 2 \mathrm{~cm}$. The tumor was completely resected and the metastasis of PENT was confirmed by pathological examination. The patient was followed-up continuously for 60 months until the preparation of this report. She remained generally healthy and normotensive, but was moderately pigmented in hands and feet. Laboratory tests revealed normal renal function and serum/urine cortisol levels. The follow-up CT scan detected no relapse or metastasis.

\section{Discussion}

PNET is rarely reported to be endocrinally active, whereas some PNETs may exhibit neuroblastoma-like properties [4, 5]. Cushing's syndrome-like endocrine symptoms in our patient were resolved following the resection of the primary lesion. The patient developed no relapse of hypertension, hypercortisolism, or pigmentation for 5 years, indicating that the endocrinal activity was derived from the PNET itself.

PNET often exhibits nonspecific symptoms. CT and MRI scans of PNET are uncharacteristic and similar to those of renal cell carcinomas [6]. The diagnosis of renal PNET depends mainly on histology, immunohistochemistry, and molecular cytogenetics [7]. The formation of a fusion gene of EWS/FLI1 encodes oncogenic transcription factors [3, 7]. In our case, CD99, a product of MIC2 secondary to EWS/FLI1 recombination was found to be positive as expected.

The major treatment for renal PNET is radical surgery. The requirement of adjuvant chemotherapy and radiation therapy remains controversial in current clinical practice $[8,9]$. In our case, the patient who underwent radical nephrectomy and perirenal lymphadenectomy, without chemotherapy or radiation therapy, has survived for at least 5 years.

Overall, PNET has a poor prognosis, with a median survival of 7.3 months in case of local or distant metastasis at the time of diagnosis. The prognostic factors mainly consist of tumor size, metastasis at diagnosis, and expression of synaptophysin. The expression of type I fusion proteins (EWS exon 7 with FLI1 exon 6-9, 60\%) is a favorable prognosis [10]. The PNET in this patient was staged as T2 without renal fatty capsule involvement, tumor thrombus and lymph node involvement in the renal region, and no distant metastasis were identified at the 
time of initial diagnosis. Additionally, the patient had a type I EWS/FLI1 fusion gene. All these factors predict a favorable survival outcome.

Renal PNET occasionally exhibits endocrine activity such as hypertension and systematically pigmentation. The differential diagnosis of renal PNET depends mainly on histologic finding of rose-ring-like architecture, immunohistochemistry detection of CD99, vimentin, CgA, Sy, and molecular biological analysis of EWS/FLI fusion gene in tumor. Confirmative genotyping and early diag- nosis may improve a patient's survival. Early diagnosis and definitive surgery may lead to a patient's long-term survival.

\section{Conclusion}

Early diagnosis and definitive surgery led to the patient's long-term survival.

\section{References}

$>1$ Thyavihally YB, Tongaonkar HB, Gupta S, Kurkure PA, Amare P, Muckaden MA, et al: Primitive neuroectodermal tumor of the kidney: a single institute series of 16 patients. Urology 2008;71:292-296.

-2 Ellinger J, Jbastian P, Hauser S, Biermann K, Muller SC: Primitive neuroectodermal tumor: rare, highly aggressive differential diagnosis in urologic malignancies. Urology 2006;68:257-262

-3 Argani P, Perez-Ordoñez B, Xiao H, Caruana SM, Huvos AG, Ladanyi M: Olfactory neuroblastoma is not related to the Ewing family of tumors: absence of EWS/FLI1 gene fusion and MIC2 expression. Am J Surg Pathol 1998;22:391-398.
-4 Jürgens H, Bier V, Harms D, Beck J, Brandeis W, Etspüler G, Gadner H, Schmidt D, Treuner J, Winkler K: Malignant peripheral neuroectodermal tumors. A retrospective analysis of 42 patients. Cancer 1988;61:349-357.

5 Fontaine C, Schots R, Braeckman J, Goossens A, Soete G, De Grève J: Long-term survival in an adult metastatic renal peripheral primitive neuroectodermal tumor (PPNET) with multimodality treatment including high-dose chemotherapy. Ann Oncol 1997;8: 691-694.

6 Thotathil ZS, Varghese A, Ragheb A: Renal cell carcinoma: the experience of Kuwait Cancer Control Center, Kuwait. Med Princ Pract 2005; 14:1-5.

$\checkmark 7$ Marley EF, Liapis H, Humphrey PA, Nadler RB, Siegel CL, Zhu X, Brandt JM, Dehner LP: Primitive neuroectodermal tumor of the kidney - another enigma: a pathologic, immunohistochemical, and molecular study. Am J Surg Pathol 1997;21:354-359.
Kuroda M, Urano M, Abe M, Mizoguchi Y, Horibe Y, Murakami M, Tashiro K, Kasahara M: Primary primitive neuroectodermal tumor of the kidney. Pathol Int 2000;50:967972.

9 Paulussen M, Ahrens S, Burdach S, Craft A, Dockhorn-Dworniczak B, Dunst J, Fröhlich B, Winkelmann W, Zoubek A, Jürgens $\mathrm{H}$ : Primary metastatic (stage IV) Ewing tumor: survival analysis of 171 patients from the EICESS studies. European Intergroup Cooperative Ewing Sarcoma Studies. Ann Oncol 1998;9:275-281.

10 Lin PP, Brody RI, Hamelin AC, Bradner JE, Healey JH, Ladanyi M: Differential transactivation by alternative EWS-FLI1 fusion proteins correlates with clinical heterogeneity in Ewing's sarcoma. Cancer Res 1999;59:14281432. 